\title{
A RARE VARIANT OF HYPERTHYROIDISM: UNILATERAL GRAVES’ DISEASE
}

Seyid Ahmet AY ${ }^{1}$, Kamil BASKOY ${ }^{1}$, Muammer URHAN² ${ }^{2}$, Ferhat DENIZ ${ }^{1}$, Arif YONEM ${ }^{1}$

1.Dep. of Endocrinology, Haydarpaşa Training Hospital, GATA; 2.Dep. of Nuclear Medicine, Haydarpaşa Training Hospital, GATA, Istanbul/TURKEY

INTRODUCTION: Despite the fact that Graves' disease(GD) almost always presents as a diffuse hyperfunctioning goiter involving both lobes of the thyroid gland, it may rarely reveal at only unilateral lobe with bilobar thyroid gland. We herein present a case of unilateral GD involving the right thyroid lobe of a bilobar gland.

CASE REPORT:A 42-year-old woman presented with symptoms and signs of hyperthyroidism; thyrotropin (TSH) was undetectable, while free thyroxine (fT4) and free triiodothyronine(fT3) were increased. A color Doppler Ultrasonography of the thyroid gland was revealed a nonhomogeneous, hypervascular and enlarged right lobe compared to the hypovascular and homogeny left thyroid lobe. Thyroid scintigraphy with Tc99m showed that uptake of the radioisotope was uniformly and unilaterally increased in the right lobe, with no uptake in the left lobe of thyroid gland, which was compatible with unilateral GD. Finally, thyroid autoantibodies were positive. Unilateral Graves' disease was diagnosed, and treated with methimazole and propronalol. In the nineth month, the complaints and laboratory of the patient were improved by antithyroid therapy, and the treatment was gradually discontiuned. Two months later, because her complains and laboratory were consistent with overt thyrotoxicosis, the antithyroid therapy was given again. As a conclusion, after the last medical treatment, she will be referred for radioiodine ablation therapy due to the recurrent disease.

CONCLUSION: This thyrotoxic patient has positive thyroid autoantibody, hypervascular and heterogeneously enlarged right thyroid lobe on ultrasonography (compared to the hypovascular and homogeny left thyroid lobe),and the uniformly distributed,increased Tc99m uptake in the right thyroid lobe pointing to existence of unilateral GD as the diagnosis. Unilateral GD is a rare condition and its pathophysiology has not been clearly elucidated. In conclusion, clinicians should be aware that Graves' disease can present with unilateral involvement of the thyroid gland. 